\title{
EDITORIAL
}

\section{The Future of Sustainable Development: Welcome to the European Journal of Sustainable Development Research}

\author{
Marc A. Rosen, Founding Editor-in-Chief ${ }^{*}$ \\ 1 University of Ontario Institute of Technology, CANADA \\ *Corresponding Author: marc.rosen@uoit.ca
}

Citation: Rosen M.A. (2017). The Future of Sustainable Development: Welcome to the European Journal of Sustainable Development Research, European Journal of Sustainable Development Research, 1:1 (2017), 1.

doi: http://dx.doi.org/10.20897/ejosdr.201701

Received: August 4, 2016; Accepted: August 20, 2016; Published: January 17, 2017

Sustainable development is an objective for humanity of crucial importance to how we develop and evolve. It is also a rapidly growing discipline that is becoming increasingly applied in numerous areas, reflecting humanity's desire to ensure its activities can be sustained into the future and do not adversely affect the ecology or environment.

Sustainable development is often defined based on the 1987 statement of the World Commission on Environment and Development (i.e., the Brundtland Commission). In that milestone document, sustainable development was defined as "development that meets the needs of the present without compromising the ability of future generations to meet their own needs." But new definitions are being developed as the discipline expands and becomes more multidisciplinary and complex.

Sustainable development has been recognized as an interdisciplinary and multidisciplinary field. The multidisciplinary nature of sustainable development is illustrated in Figure 1, where many stakeholders in the debates about sustainable development are shown. Some stakeholders are contributors to the advancement of the sustainable development discipline, others are users of the methods and tools that are being developed, and some are both.

Attitudes among people and practitioners towards sustainable development seem to becoming more positive with time. There is a growing focus on the implementation of sustainable development concepts, actions and measures, by both individual and organizations.

Progress and advances are being made continually. An important example of this is the recent adoption of the 2030 Agenda for Sustainable Development - which includes a set of 17 Sustainable Development Goals - at the 70th Session of the UN General Assembly in 2015. The objectives include ending poverty, combating inequality and injustice, and addressing climate change by 2030 .

But given the field of sustainable development is still very much in its infancy, advances are required to allow the discipline to advance and grow in an organized manner and achieve its potential.

To help in disseminating the growing amount of sustainable development activity by researchers, practitioners and decision makers throughout the world, journals focusing on sustainable development are needed. These are increasingly important as the field of sustainable development expands, making it progressively vital to have meaningful and productive interactions among sustainable development researchers in varying fields (e.g., societal, economic, environmental, technical, health).

The European Journal of Sustainable Development Research has been launched to help meet the growing need for publications that foster fruitful discussions between researchers from different fields, and permit cross-fertilizing ideas to be exchanged. As a multidisciplinary scholarly journal, with a scope straddling technical, environmental, economic and social fields, the European Journal of Sustainable Development Research has been established to provide a useful forum for disseminating and sharing research related to sustainable development, in a manner that benefits both the research community and practitioners and decision makers interested in sustainable development and its 


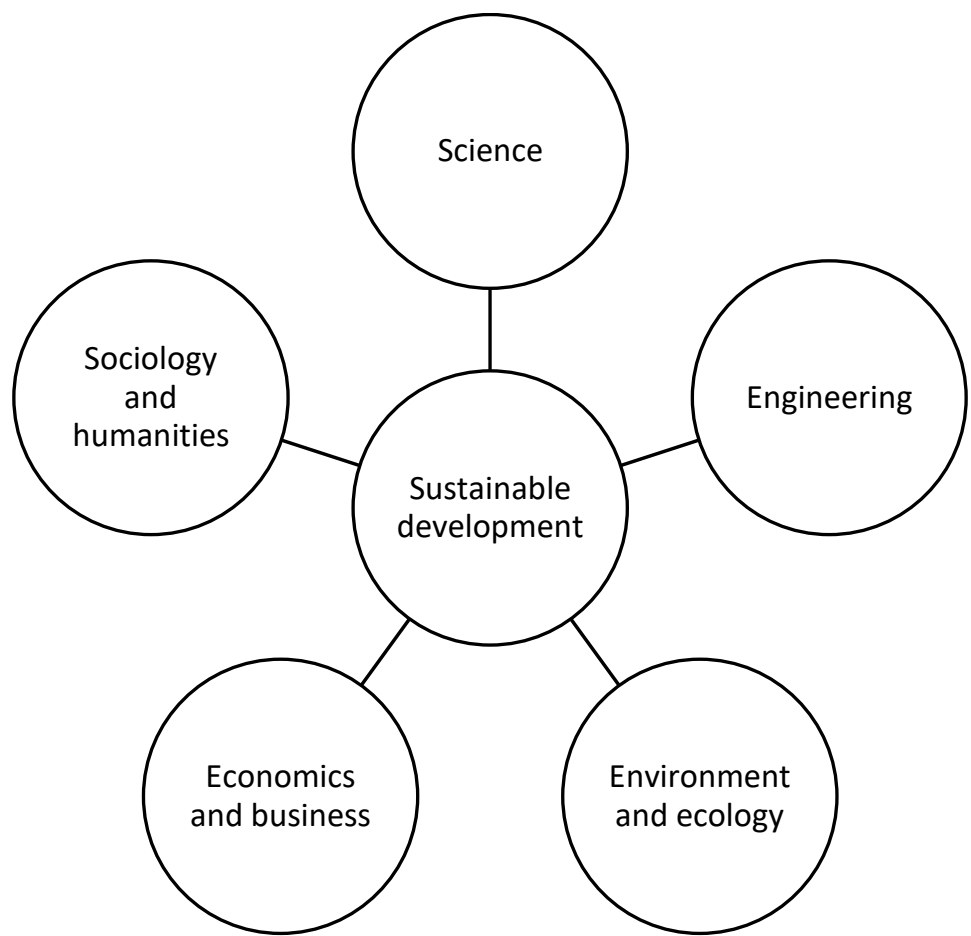

Figure 1. The multidisciplinary nature of sustainable development, indicating some of the disciplines that are stakeholders in the field.

applications. The journal will include special issues on select and timely topics in order to ensure important aspects of sustainable development receive adequate attention, and an editorial board of highly qualified experts from many disciplines has been appointed to guide the journal's evolution and adequately represent the breadth of the fields of encompassed by sustainable development.

To help promote and facilitate sustainable development, researchers are invited to publish their research relating to sustainable development in the European Journal of Sustainable Development Research, including work that is theoretical or computational or experimental in nature, and investigations emanating from the natural sciences, engineering and the applied sciences, economics, the social sciences and humanities, and other fields. Articles that both elicit new ideas, and challenge convention and go beyond accepted paradigms, are welcome. In addition, reviews and articles on projects by organizations, governments and others are also solicited, to further provide useful information and guidance to readers and to address challenges related to sustainable development and provide solutions.

I expect that the European Journal of Sustainable Development Research will become a leading journal for research on sustainable development, contributing to the growth of the field, to advances in sustainable development technology and methods, and to improved sustainable development-related decision making and policy development. So, I invite you to participate in the growth of the field of sustainable development by submitting original research and comprehensive review articles to the European Journal of Sustainable Development Research. In this way, the European Journal of Sustainable Development Research can become an important contributor to humanity's desire to achieve sustainable development. 